\title{
A New Hydraulic Crash Machine for Composite Structures
}

\author{
Walid Harizi $\cdot$ Aurélie Monnin · Zoheir Aboura • \\ Malk Benzeggagh
}

Received: 15 November 2014/Accepted: 7 January 2015/Published online: 14 January 2015

(C) Society for Experimental Mechanics, Inc 2015

\begin{abstract}
This paper describes the design and implementation of a new innovative machine for hydraulic crash of composite structures at a laboratory scale. This machine can be classified in the category of low velocity impact machines. Its first use was conducted on a glass fiberreinforced polymer composite plate (GFRP), impacted by a fluid (water) at 10 bars during $10 \mathrm{~ms}$. Initial results, in terms of pressure and deflection, show the potential of this machine for studying the dynamic response of a structure in hydraulic crash test.
\end{abstract}

Keywords Polymer-matrix composites (PMCs) · Woven fabrics $\cdot$ New machine $\cdot$ Impact behavior $\cdot$ Hydraulic crash

\section{Introduction}

GFRP composite laminate materials are largely used for structural applications, such as automobile, railway, wind energy, etc. thanks to their high strength-to-weight ratios. Hence, there is an increasing need of studying their mechanical behavior in case of damage. Indeed, damage of composite materials is a very complex phenomenon due to their structural heterogeneity and anisotropy added to the inevitable internal defects originated from manufacturing process [1-4], such as porosity, misalignment of fibers, etc.

Even though they display interesting mechanical properties, thermosetting polymer matrices also present undeniable drawbacks: low-temperature storage, very long

W. Harizi ( $₫)$ · A. Monnin · Z. Aboura · M. Benzeggagh Université de Technologie de Compiègne, Laboratoire de Mécanique Roberval UMR CNRS 7337, Dept GM, CS 60319, 60203 Compiègne Cedex, France

e-mail: walid.harizi@utc.fr; walid.harizi@gmail.com curing process, and hand-made draping, which cause most of the irreversible defects during the manufacturing process. Thereby, high performance thermoplastic resins offer a promising alternative to thermosetting resins. Indeed, semi-crystalline thermoplastic resins offer a number of advantages over conventional thermosetting resins (such as epoxies): a high degree of chemical resistance, excellent damage and impact resistances, and they may be used over a wide range of temperatures. Following an impact, polymer matrix composite laminates may undergo delamination, resulting in low damage tolerance, which is of great concern for aircraft applications [5, 6].

Low velocity impact is one of the most detrimental solicitations for composite laminates because it drastically reduces the residual mechanical properties of the structure [7-10].

The strain rate of different mechanical tests may range from much higher (e.g., $\sim 10^{2}$ to $10^{3} \mathrm{~s}^{-1}$ due to impact from a fall to $\sim 10^{2}$ to $10^{6} \mathrm{~s}^{-1}$ due to a ballistic impact) to lower (from $\sim 10^{-6}$ for creep under a constant load to $10^{-2}-10^{-3}$ for quasistatic tests) extremes.

Strain rates from 1 to $10^{2} \mathrm{~s}^{-1}$ can be achieved with specialized machines utilizing a pendulum or drop tower. Classic impact testing includes Charpy, Izod and dropweight impacts [11-16]. All these tests measure the impact energy absorption (or "impact toughness") and the damage resistance. The Charpy test loads a notched specimen in three-point bending, while the Izod test loads a notched specimen as a cantilevered beam. The bulging test involves the application of a differential pressure that induces a deflection and causes the membrane to inflate like a balloon. This test is often used for the determination of the residual stress (the membrane tension) due to fabrication process and of the Young's modulus of a film [17, 18]. The interference fringes after a computer processing allow a 
measure of the displacement for each point of the membrane surface [19].

High strain rates from $10^{2}$ to $10^{4} \mathrm{~s}^{-1}$ can be achieved using a split Hopkinson pressure bar, where a specimen is placed in between the ends of two straight, perfectly aligned bars called the incident and transmitted bars [20, 21]. At the end of the incident bar away from the specimen, an incident stress wave is created as the striker bar impacts the incident bar after being accelerated by a compressed gas gun. At the specimen interface, part of the stress wave is reflected back down the incident bar and another part is transmitted through the specimen and into the transmitted bar. All three bars are composed of the same material of known properties, typically high strength steel, although softer and harder materials may be used for testing softer materials and harder materials, respectively. Strain gauges placed on the incident and transmitted bar allow the measurement of strains, strain rates, and ultimately, using known properties for the bar, a true stress-strain curve [21]. The strain rate can be controlled by varying the impact velocity (via gas pressure in the gun) and specimen size. Specimens are typically loaded in compression, although tension and torsion are also possible. Bending configurations may be used to measure dynamic fracture toughness [22, 23]. Direct measurements of specimen deformation and crack growth require the use of high speed videography. While split Hopkinson bar testing is quantitative, unlike most pendulum or drop tower tests, the lack of a feedback control system typically results in an iterative design of experiments and a lack of standards. Very high strain rates from $10^{4}$ to $10^{6} \mathrm{~s}^{-1}$ can be achieved using the acceleration of projectiles or the detonation of explosives to generate shock waves [20].

Several mechanical parts may be subjected to a crash during their service. In the case of fluid tanks made with thermoplastic composite material, upon crash (tank/soil contact), fluid filled the tank has a major contribution in the total failure of structure as it is impacting its internal walls. Thus, it is a fluid/solid contact, denoted hydraulic crash. In contrast, none of the previously mentioned impact methods is able to investigate the mechanical behavior in this crash configuration since there is no fluid in the impact operation. The originality of this study lies in particular in the design and establishment of a new hydraulic crash machine. Composite structures are then tested and their dynamic response is analyzed.

This paper presents the goal and design of the new hydraulic crash machine in "Goal and Design of the New Hydraulic Crash Machine" section, and the first results obtained on thermoplastic composite specimens with glass fiber-reinforced polyamide 6 resin (PA6) in both "Dynamic Crash Test and Experimental Procedures" and "Results and Discussion" sections.
Goal and Design of the New Hydraulic Crash Machine

The goal of this machine is the study of the deformability of composite materials after a hydraulic crash by water. It can be used for several purposes: safety check, destructive tests to find the limit pressure and limit deflection of composite panels, verification of bonding joints, the tightness and the determination of the off-plan displacement field.

The new machine (Figs. 1, 2) is formed of a metal enclosure (1) in stainless steel, with a thickness of $8 \mathrm{~mm}$, filled with water. Test material is clamped at the end of the enclosure by eight bolts (with a diameter of $14 \mathrm{~mm}$ ) and a flange. A metal mass (2) (net weight of $750 \mathrm{~kg}$ ) is connected by magnets to a mechanical system (string/sprocket) which promotes its translational guidance along the $Z$ axis. In free fall, the mass (2), equipped with a mechanical cam (3) at the end of its side surface, generates a translational movement along the $X$ axis of a hydraulic jack (4) which compresses water (assumed incompressible) that comes impacting the composite plate embedded at the end of the enclosure. Thus, the action of the falling weight pushes water so that it directly contacts the test plate. A pneumatic chamber (5) to adjust enclosure pressure is implanted just before its convergence. It ensures a pressure of 10 bars inside the metal enclosure during hydraulic crash test; if the dynamic pressure generated due to the free fall of the mass (2) exceeds 10 bars, the pneumatic jack (5) (Fig. 1) descends from its upper position to a lower position to keep a pressure of 10 bars inside the enclosure. The control system of crash pressure is managed by a booster powered by an air compressor. The hydraulic crash cycle is managed by an automation system. This new machine allows studying a crash response of circular structures (panels) with a varying thickness and a wide range of impact velocities by varying the free fall height of the mass or the stroke of hydraulic jack. A 3D representation of the crash machine is illustrated in Fig. 2. All equipment are surrounded by a safety guard to protect the operator.

\section{Dynamic Crash Test and Experimental Procedures}

\section{Material}

The composite material used in this study is a woven-ply glass fiber-reinforced semi-crystalline thermoplastic matrix, PA6. Thermoplastic resin is presented in film form with a thickness of $125 \mu \mathrm{m}$ (from Arkema, France). The characteristics of PA6 are summarized in Table 1. However, the used twill $2 / 2$ fabric is from "Porcher Composites" with E glass type. The density of E glass fiber is $2.54 \mathrm{~g} / \mathrm{cm}^{3}$ with a diameter $9 \mu \mathrm{m}$. The total number of 
Fig. 1 Overall drawing of hydraulic crash machine

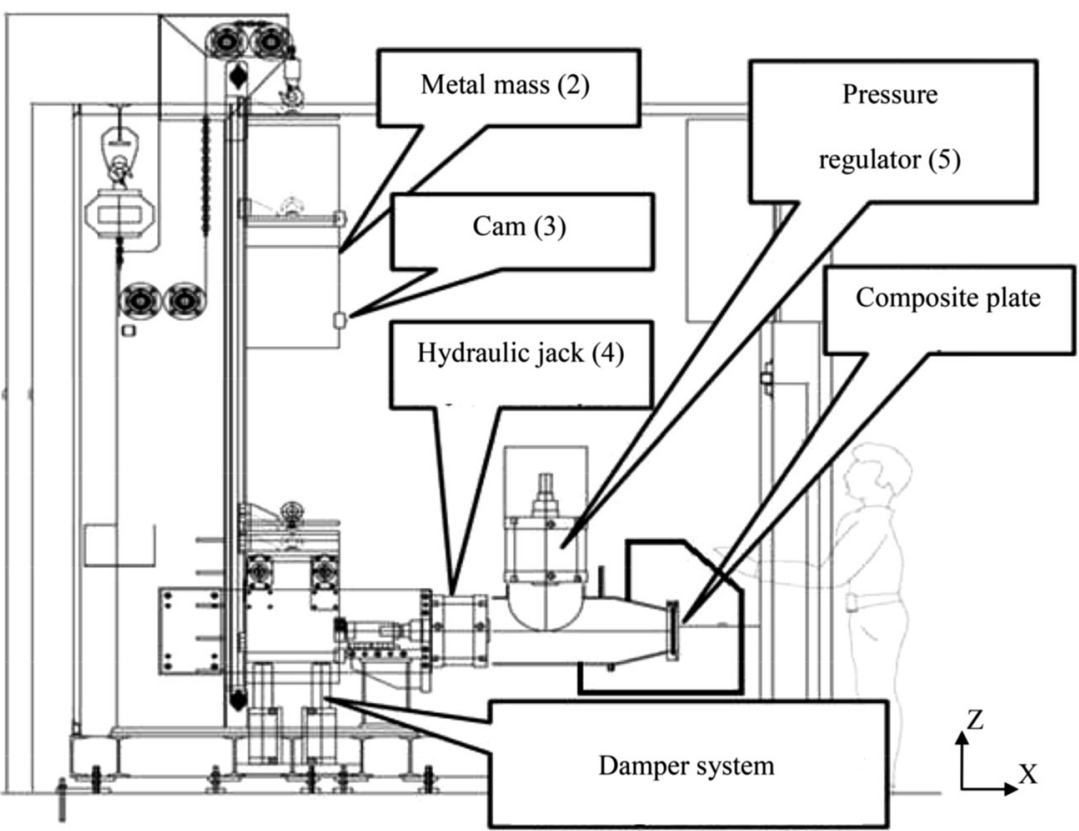

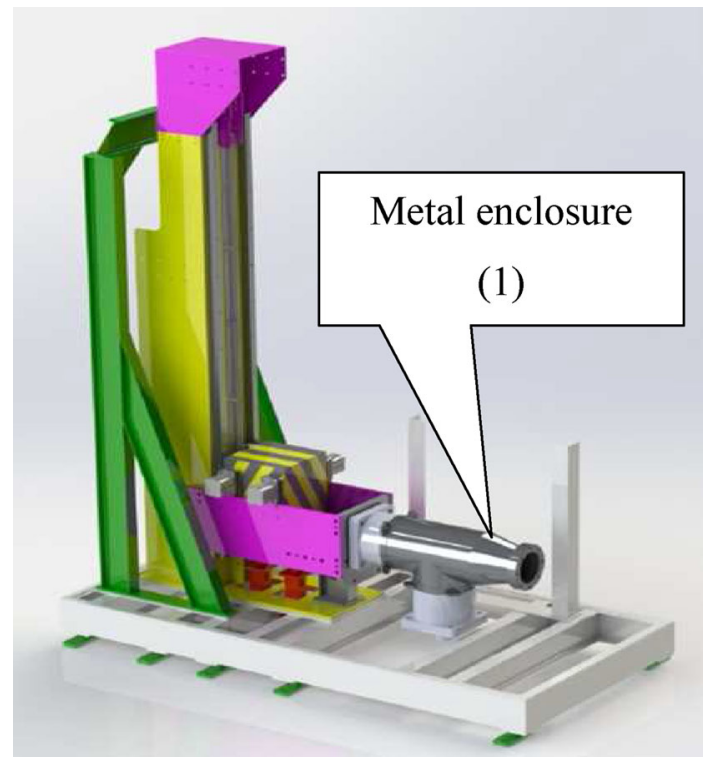

Fig. 2 3D representation

Table 1 Characteristics of PA6 resin

\begin{tabular}{ll}
\hline Designation & Values \\
\hline Melt temperature $\left({ }^{\circ} \mathrm{C}\right)$ & 220 \\
Glass transition temperature $\left({ }^{\circ} \mathrm{C}\right)$ & $50-60$ \\
Young's modulus $(\mathrm{MPa})$ & 3,200 \\
\hline
\end{tabular}

filaments in the warp of glass fabric is 2,112 . In the representation of the weave pattern in column 5 of Table 2 , warp yarns are shown by a black color whereas white color is attributed to weft yarns.
The manufacturing method chosen was the compression molding process by thermo-stamping:

It is performed using a stamping press which exerts a maximum closing pressure $P_{\max }=35$ bars between two heating trays. Composite plate should have a thickness of $3 \mathrm{~mm}$ and a fiber volume fraction of $40 \%$. The required plies number of twill fabric in glass fiber is 8 . For the eight plies, we need 16 sheets of thermoplastic resin PA6 because the stacking must be symmetrical to avoid the appearance of residual stresses (Fig. 3). During the compression process, vacuum is maintained in order to evacuate the air trapped within the stacking, ensuring a low rate of voids in the composite plate at the end of manufacturing cycle. The processing temperature was fixed at $250{ }^{\circ} \mathrm{C}$. Compression time was optimized experimentally and was set at $25 \mathrm{~min}$ for manufacturing a plate with the dimensions $380 \times 380 \mathrm{~mm}^{2}$. The cooling rate of the two heating trays was fixed at $5{ }^{\circ} \mathrm{C} / \mathrm{min}$. Demoulding was carried out at $30{ }^{\circ} \mathrm{C}$.

In this study, the specimen of hydraulic crash test has a circular form with a diameter of $\phi=230 \pm 1 \mathrm{~mm}$ and a thickness of $3 \mathrm{~mm}$ (Fig. 4). After fixing and clamping at the end of the metal enclosure, the impacted useful diameter is only $190 \mathrm{~mm}$. In total, five samples were tested according to the crash hydraulic cycle shown in Fig. 5.

\section{Hydraulic Crash Procedure}

The new machine is used to study the mechanical behavior of composite structures during a hydraulic crash (fluid/solid contact). In this study, we want to lead the hydraulic crash 
Table 2 Characteristics of yarns used in the manufacturing of the twill $2 / 2$ fabric

\begin{tabular}{|c|c|c|c|c|c|c|c|c|c|}
\hline \multirow[t]{2}{*}{ Product } & \multicolumn{2}{|l|}{ Yarn type } & \multirow[t]{2}{*}{$\begin{array}{l}\text { Weight } \\
\left(\mathrm{g} / \mathrm{m}^{2}\right)\end{array}$} & \multirow[t]{2}{*}{ Weave pattern } & \multirow[t]{2}{*}{ Sizing } & \multicolumn{2}{|c|}{ Nominal texture } & \multicolumn{2}{|c|}{$\begin{array}{l}\text { Mass } \\
\text { distribution } \\
(\%)\end{array}$} \\
\hline & Warp & Weft & & & & $\begin{array}{l}\text { Warp } \\
\text { (yarn/ } \\
\mathrm{cm})\end{array}$ & $\begin{array}{l}\text { Weft } \\
\text { (counts/ } \\
\mathrm{cm})\end{array}$ & Warp & Weft \\
\hline $\begin{array}{r}\text { E glass } \\
\text { fabric }\end{array}$ & $\begin{array}{l}\text { EC9 } 68 \times 5 \text { t0 }(340 \\
\text { tex })\end{array}$ & $\begin{array}{l}\text { EC9 } \\
273\end{array}$ & 399 & Twill 2/2 & K506 & 6.0 & 6.6 & 53 & 47 \\
\hline
\end{tabular}

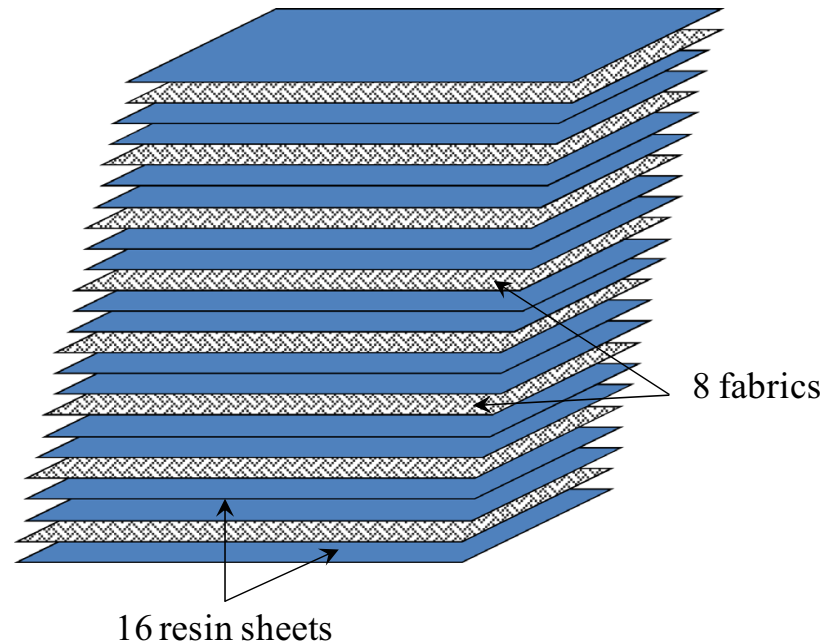

Fig. 3 Stacking sequence of 8 twill fabrics and 16 resin sheets

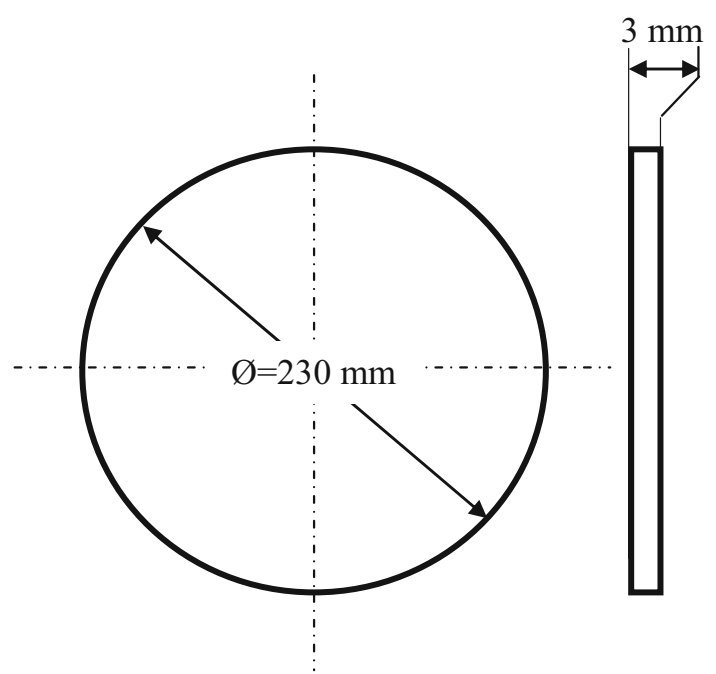

Fig. 4 Dimensions of specimen used in hydraulic crash test

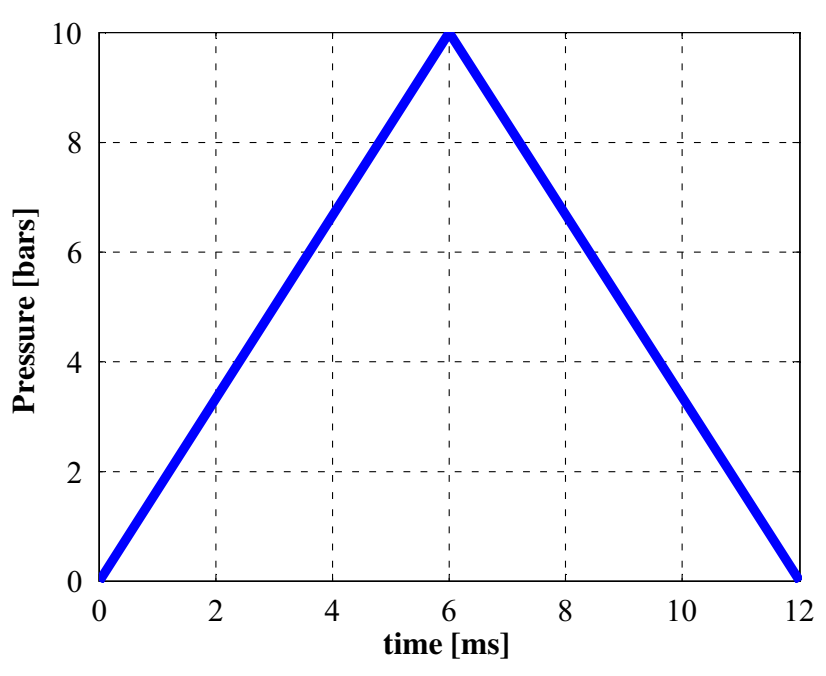

Fig. 5 Hydraulic crash cycle

test at 10 bars during a time that must not exceed $6 \mathrm{~ms}$. We estimate a total duration of $12 \mathrm{~ms}$ for whole cycle (Fig. 5). Two pressure transducers TP1R of 10 bars (AEP transducers, with a nominal sensitivity $2 \mathrm{mV} / \mathrm{V}$ and a maximum permissible pressure of $150 \%$ ) are located on two sides of the metal enclosure, one in the right and another in the left, just before reaching the composite plate of few centimeters (Fig. 6a). Hydraulic crash machine is instrumented with a laser system to measure the deflection of composite plate at its center. A fast camera (model FASTCAM SA 1.1 of "Photron", with a maximum speed of 5,457 frames per second at a full resolution of 1 mega pixel $(1024 \times 1024))$ is used to film the fast crash scene (Fig. 6b). Finally, we instrumented the enclosure by two strain gauges (type TML FCA-11, with a gauge factor of 2.1) on its upper surface (Fig. 7) to ensure that it does not deform during hydraulic crash test. 

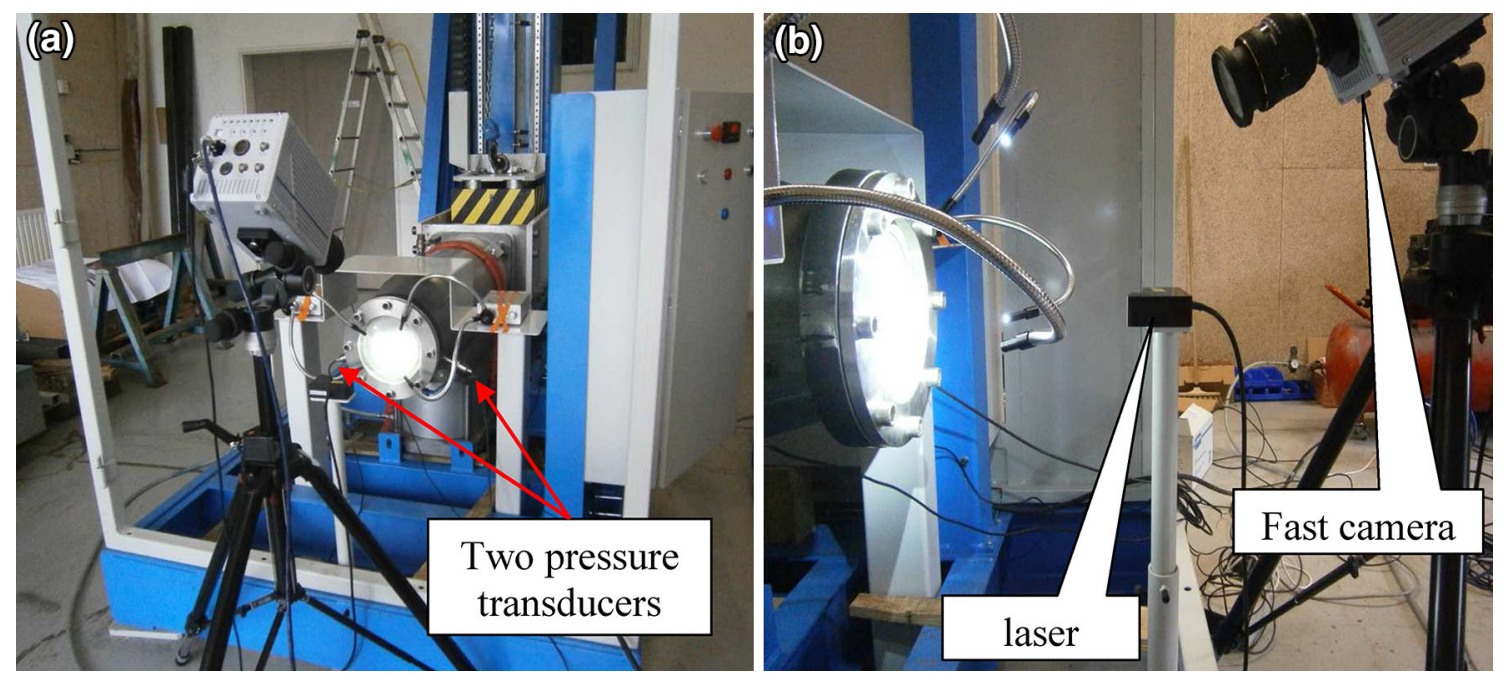

Fig. 6 Instrumentation of the crash machine with two pressure transducers (a), a laser system and a fast camera (b)

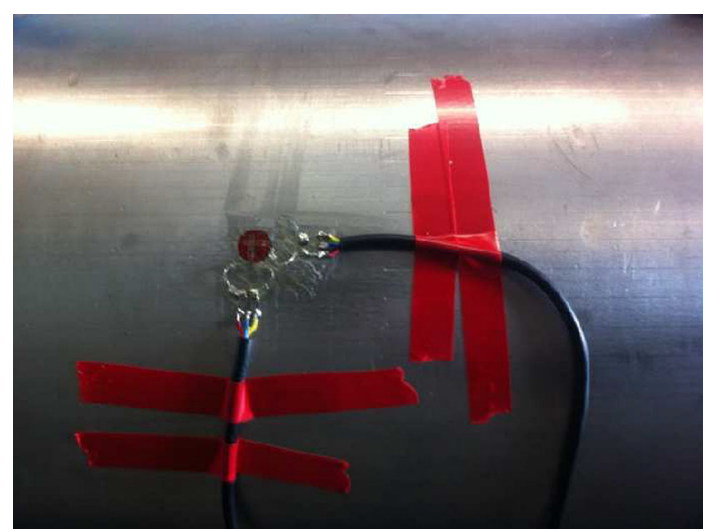

Fig. 7 Two strain gauges implanted on the lateral surface of the enclosure

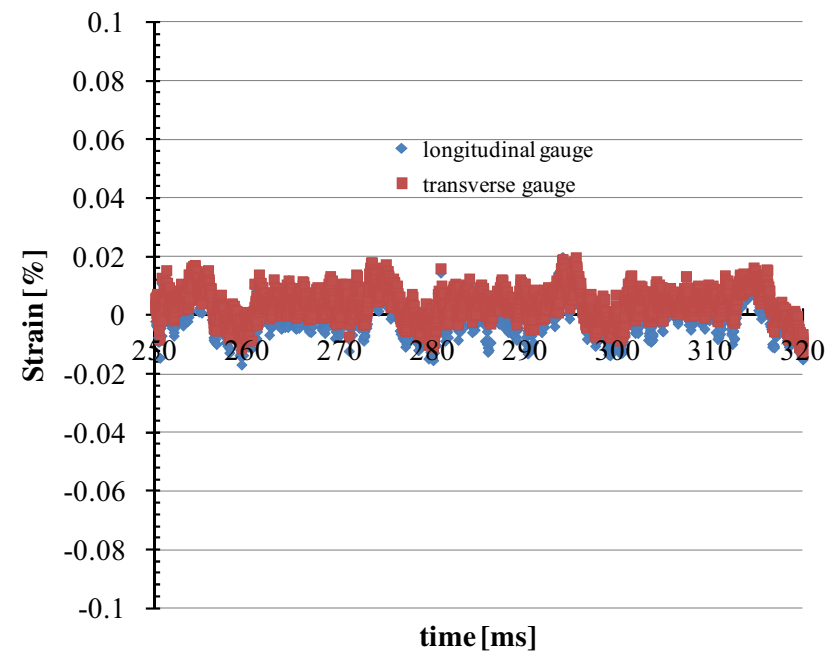

Fig. 8 The non-deformability of the metal enclosure during hydraulic crash test conducted at 10 bars

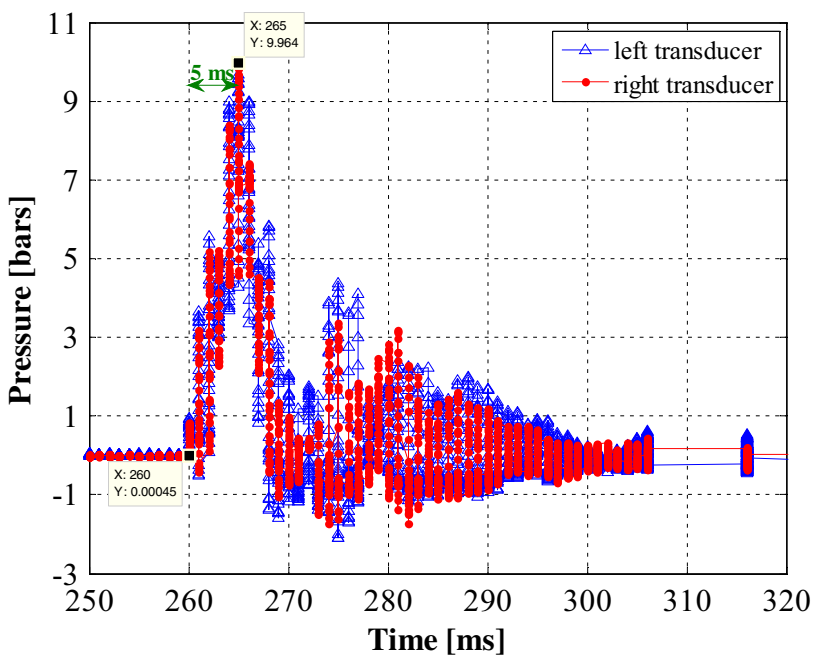

Fig. 9 Typical behavior of PA 6/glass fibers composite material under a hydraulic crash test conducted at 10 bars

\section{Results and Discussions}

\section{Enclosure Strain}

The strain of the enclosure measured by the two strain gauges is shown in Fig. 8, it is virtually zero for a time window of $70 \mathrm{~ms}$ of crash cycle conducted at 10 bars.

\section{Pressures and Deflection}

The two pressures (right and left) recorded by the two pressure transducers are shown in Fig. 9. They have the same variation and reach 10 bars just during $5 \mathrm{~ms}$. The imposed constraint by our industrial partner is well respected. The total cycle duration including the load climb 


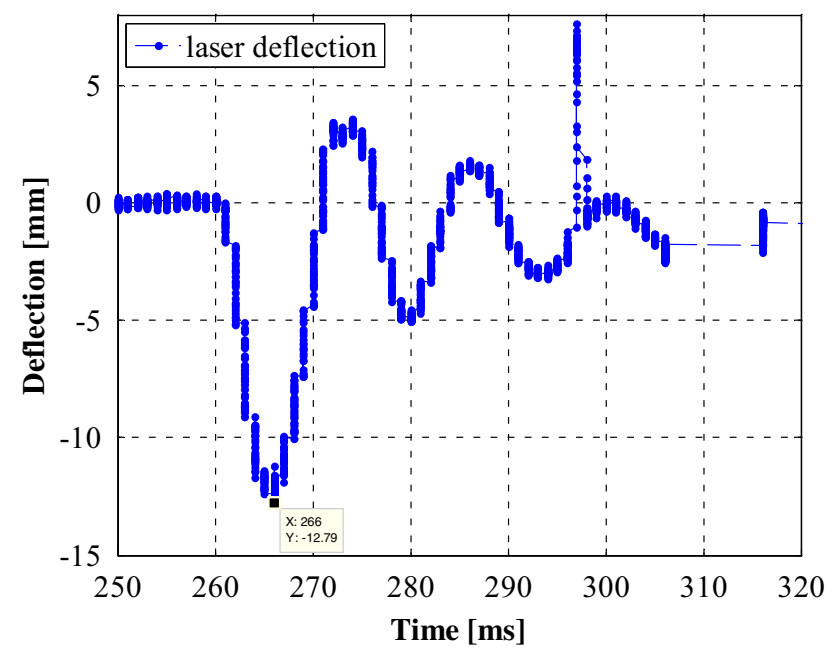

Fig. 10 Typical deflection of PA 6/glass fibers composite material under a hydraulic crash test at 10 bars

and descent is $10 \mathrm{~ms}$. However, it should be noted that after undergoing the impact at 10 bars, composite plate PA6/glass fibers presents a "spring" effect resulting from tensile (positive pressure) and compression (negative pressure) phases. This is due to the plate reaction after crash.

The maximum deflection measured by the laser system in the center of composite plate is $12.67 \mathrm{~mm}$, corresponding at the maximum pressure of 10 bars with an offset of $1 \mathrm{~ms}$. The two pressure sensors detect the shock wave before the latter reaches the composite plate. After, according to its "spring" effect, the plate deforms in a positive and negative senses (Fig. 10). Based on both Figs. 9 and 10, the crash velocity can be evaluated at $2.53 \mathrm{~m} / \mathrm{s}$, which corresponds to a low velocity impact case.

\section{Conclusions}

In this study, a new hydraulic crash machine has been designed and implemented to study the dynamic behavior of thermoplastic composite plates due to a shock conducted at 10 bars during a period of $10 \mathrm{~ms}$. This machine can be classified in the group of low velocity impact (strain rate does not exceed $10^{2} \mathrm{~s}^{-1}$ ).

It has been instrumented by a fast camera and a laser system for measuring the deflection in the center of plate. Preliminary results of deflection and pressure, obtained on a plate PA6 resin/glass fibers are promising. The study will be continued according to two main research themes; the first is experimental in trying to determine an out-of-plane strain field of the entire useful diameter, this requires the use of two fast cameras (stereo-correlation method). While the second axis addresses the numerical simulation by predicting the real dynamic behavior. Currently, crash tests are underway trying to vary the free fall height of metal mass and evaluate the strain rate by instrumenting the composite plate with a strain gauge at its center.

Acknowledgments The authors would like to thank the Région of Picardie, France, the patron of "ESCOTHp" Project which financed the research presented in this paper. The following affiliations are acknowledged: Mines Douai School, ENSAIT School, MS Composites company and Zodiac Aerospace group (France).

\section{References}

1. Christensen RM (2005) Mechanics of composite materials. Dover Publications, New York

2. Colombo C, Vergani L, Burman M (2012) Static and fatigue characterization of new basalt fibre reinforced composites. Compos Struct 94:1165-1174

3. Harizi W, Chaki S, Bourse G, Ourak M (2014) Mechanical damage assessment of glass fiber-reinforced polymer composites using passive infrared thermography. Compos Part B 59:74-79

4. Harizi W, Chaki S, Bourse G, Ourak M (2014) Mechanical damage assessment of polymer-matrix composites using active infrared thermography. Compos B 66:204-209

5. Vieille B, Casado VM, Bouvet C (2013) About the impact behavior of woven-ply carbon fiber-reinforced thermoplastic- and thermosetting-composites: a comparative study. Compos Struct 101:9-21

6. Vieille B, Casado VM, Bouvet C (2014) Influence of matrix toughness and ductility on the compression- after-impact behavior of woven-ply thermoplastic- and thermosetting- composites: a comparative study. Compos Struct 110:207-218

7. Cantwell WJ, Morton J (1991) The impact resistance of composite materials-a review. Composites 22(5):347-362

8. Jang BP, Kowbel W, Jang BZ (1992) Impact behavior and impact-fatigue testing of polymer composites. Compos Sci Technol 44(2):107-118

9. Abrate S (1998) Impact on composites structures. Cambridge University Press, Cambridge

10. Hancox NL (2000) An overview of the impact behavior of fibrereinforced composites. In: Reid SR, Zhou G (eds) Impact behavior of fiber-reinforced composite materials and structures. CRC Press, Woodhead Pub. Ltd., Baco Raton

11. Lascoup B, Aboura Z, Khellil K, Benzeggagh M (2010) Impact response of three-dimensional stitched sandwich composite. Compos Struct 92:347-353

12. Siewert TA, Manahan MP Sr., eds (2000) Pendulum impact testing: a century of progress. STP 1380. American Society for Testing and Materials, West Conshohocken

13. ASTM E23-07 (2007) Standard test methods for determining the notched bar impact testing of metallic materials. American Society for Testing and Materials, West Conshohocken

14. ASTM D256-10 (2010) Standard test methods for determining the Izod pendulum impact resistance of plastics. American Society for Testing and Materials, West Conshohocken

15. ASTM D6110-10 (2010) Standard test methods for determining the Charpy impact resistance of notched specimens of plastics. American Society for Testing and Materials, West Conshohocken

16. ASTM D7136/D7136M-12 (2012) Standard test method for measuring the damage resistance of a fiber-reinforced polymer matrix composite to a drop-weight impact event. American Society for Testing and Materials, West Conshohocken

17. Small MK, Nix WD (1992) J Mater Res 7:1553 
18. Bonnotte E, Delobelle P, Bornier L, Trolard B, Tribillon G (1997) Two interferometric methods for the mechanical characterization of thin films by bulging tests. Application to single crystal of silicon. J Mater Res 12:2234-2248

19. Basrour S, Robert L, Delobelle P (2000) Measurement of residual stresses in a plate using bulging test and a dynamic technique: application to electroplated nickel coatings. Mater Sci Eng A288:160-163
20. Meyers MA (1994) Dynamic behavior of materials. Wiley, New York

21. Chen W, Song B (2010) Split Hopkinson (Kolsky) bar design, testing and applications. Springer, New York

22. Ravi-Chandar K (2004) Dynamic fracture. Elsevier, Amsterdam

23. Kulin RM, Jiang F, Vecchio KS (2011) Effects of age and loading rate on equine cortical bone failure. $\mathrm{J}$ Mech Behav Biomed Mater 4:57-75 